\title{
Pseudoaneurysm following aortic homograft: clinical implications?
}

E Oechslin, T Carrel, $M$ Ritter, Ch Attenhofer, L von Segesser, W Kiowski, M Turina, R Jenni

\begin{abstract}
Objective-To determine the prevalence of pseudoaneurysm formation after aortic (left ventricular outflow tract) homograft implantation and to evaluate predisposing factors.

Methods-Echocardiographic data were analysed in 30 patients for evidence of pseudoaneurysm formation after homograft implantation. Pseudoaneurysm was characterised as a perfused echo-free space between the homograft and the native aortic wall communicating with the left ventricular outflow tract. Clinical data were analysed for potential predisposing factors for pseudoaneurysm formation.
\end{abstract}

Results-Pseudoaneurysms were found in 22 of 30 patients. Mean age, length of follow up after surgery, aortic systolic pressure gradient $\left(\begin{array}{lllll}15 & (S D & 12\end{array}\right) \quad v \quad 10$ (4) $\mathrm{mm} \mathrm{Hg}$ ), aortic root diameter, and size of the homografts were comparable in patients with and without pseudoaneurysm. Preoperative infection, operating techniques, and whether first or reoperation did not affect pseudoaneurysm formation. However, pseudoaneurysms were often localised at the site of an abscess or a paravalvular leak after eradicated prosthetic valve endocarditis. Conclusions-(1) Doppler echocardiography demonstrates that pseudoaneurysm formation is common after aortic homograft implantation. (2) A prospective study is needed to clarify the prognostic importance of pseudoaneurysms. (3) The high incidence of pseudoaneurysm formation may lead to an improvement of surgical technique (application of fibrin glue).

(Br Heart f 1995;74:645-649)

Keywords: aortic homograft; pseudoaneurysm; Doppler echocardiography

Since the introduction of homograft for aortic valve surgery by Ross $^{1}$ and Barratt-Boyes, ${ }^{2}$ aortic valve replacement and aortic root reconstruction with this material has become a well accepted surgical method of treating endocarditis and its complications, with long term results as good as or better than bioprosthesis..$^{3-5}$ Excellent results in isolated primary aortic valve replacement with a homograft have been reported recently; hospital mortality was
$1 \%$ and probability of survival without reoperation for cusp failure after 10 years was $80 \% .^{6}$ Degenerative lesions leading to stenosis or regurgitation related to geometric distortion of the aortic homograft are rare long term problems. ${ }^{67}$ Although an infection may destroy the aortic homograft, this complication seems to be less frequent than after prosthetic valve replacement. ${ }^{689}$ Aortic valve replacement and aortic root reconstruction with a composite tube-valve homograft is recommended as first choice treatment in patients with acute endocarditis with or without aortic root destruction or annular abscess; it is associated with a lower incidence of recurrent infection than mechanical or bioprosthesis. ${ }^{10-12}$ Moreover, aortic homograft implantation is considered to be the treatment of first choice in patients with contraindications for mechanical prosthesis or in whom long term anticoagulation is undesirable. ${ }^{61213}$

Pseudoaneurysm development after composite graft replacement of the aortic valve and the ascending aorta is a well described complication. ${ }^{14-16}$ In contrast, there are only a few reports describing pseudoaneurysms after homograft implantation. ${ }^{6}{ }^{17} 18 \mathrm{We}$ decided to assess systematically the incidence and predisposing factors for pseudoaneurysm formation after detection of a perfused echo-free space between the aortic homograft and the native aortic wall during routine postoperative Doppler echocardiography.

\section{Methods}

PATIENT POPULATION

We examined 30 adult patients by two dimensional Doppler echocardiography, operated by the same team between 1989 and 1993, and referred to the echocardiographic laboratory for postoperative assessment of aortic homograft function. Out of a series of more than 200 homografts, only adult patients with an aortic homograft were included; children (age $<16$ years) were not included in the analysis. After incidental detection of a perfused echofree space between the native aortic wall and the aortic homograft in one patient, we retrospectively reviewed the Doppler echocardiographic examinations in all previously implanted homografts $(n=21)$ and prospectively analysed all subsequently operated patients ( $n=9)$ for evidence of pseudoaneurysm formation. The mean age was 45 (SD 15) years (range 19 to 76 ), the mean follow up 7 (10) months (range 1 to 41 ). 
Figure 1 Pseudoaneurysm: partial dehiscence of the proximal suture line resulting in an echo-free space between the native aortic wall and the aortic homograft inflated by blood arising from the left ventricular outflow tract. Ao, aorta; LVOT, left ventricular outflow tract.
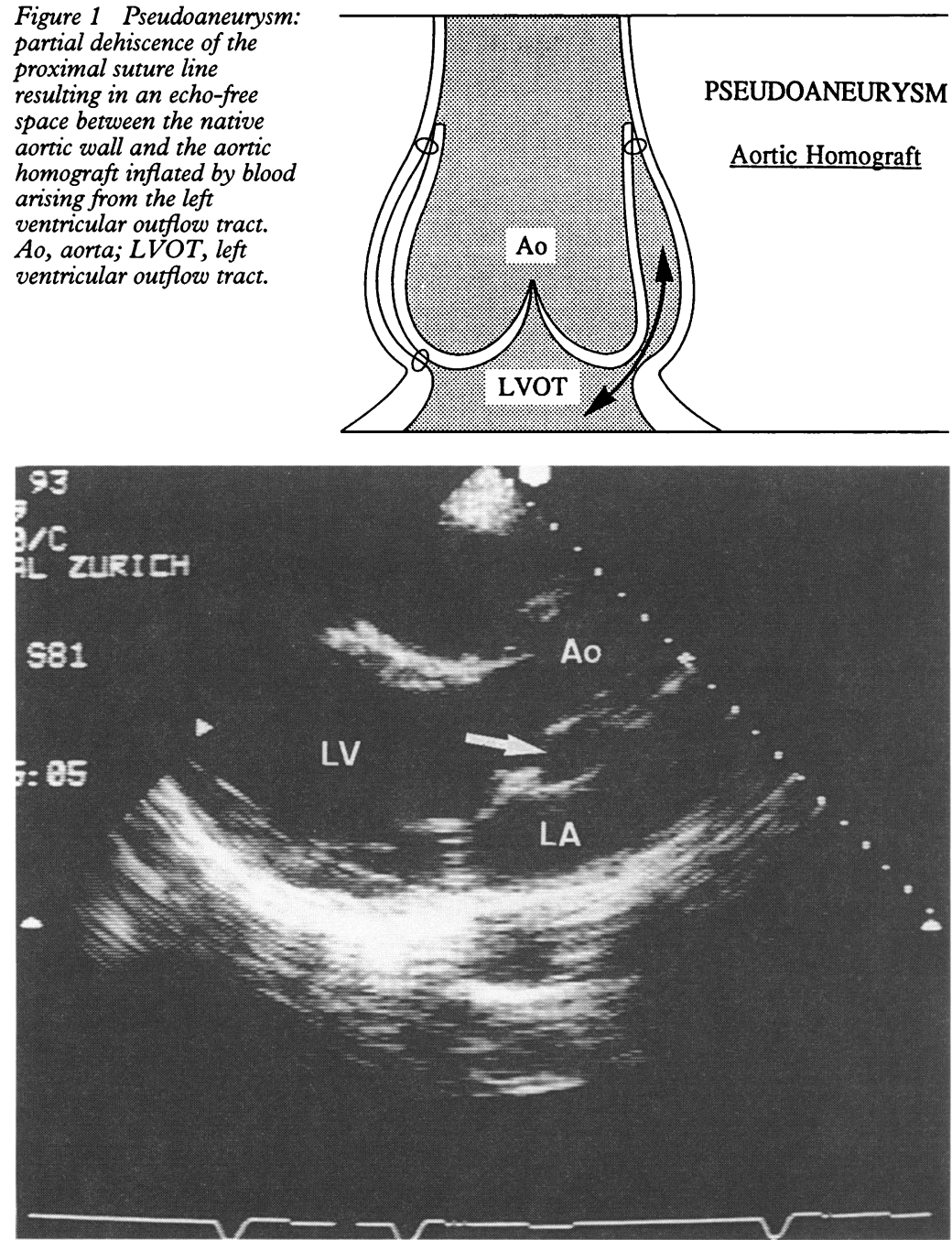

Figure 2 Parasternal long axis view (end systolic stop frame) of a 53 year old man: a large pseudoaneurysm (bold arrow) is seen in the non-coronary sinus 11 months after aortic homograft implantation. Calibration scale is indicated on the right side of the image; the distance between two dots equals $1 \mathrm{~cm}$. A peripheral lead of the electrocardiogram is displayed at bottom of the figure. Ao, aorta; $L A$, left atrium, $L V$, left ventricle.

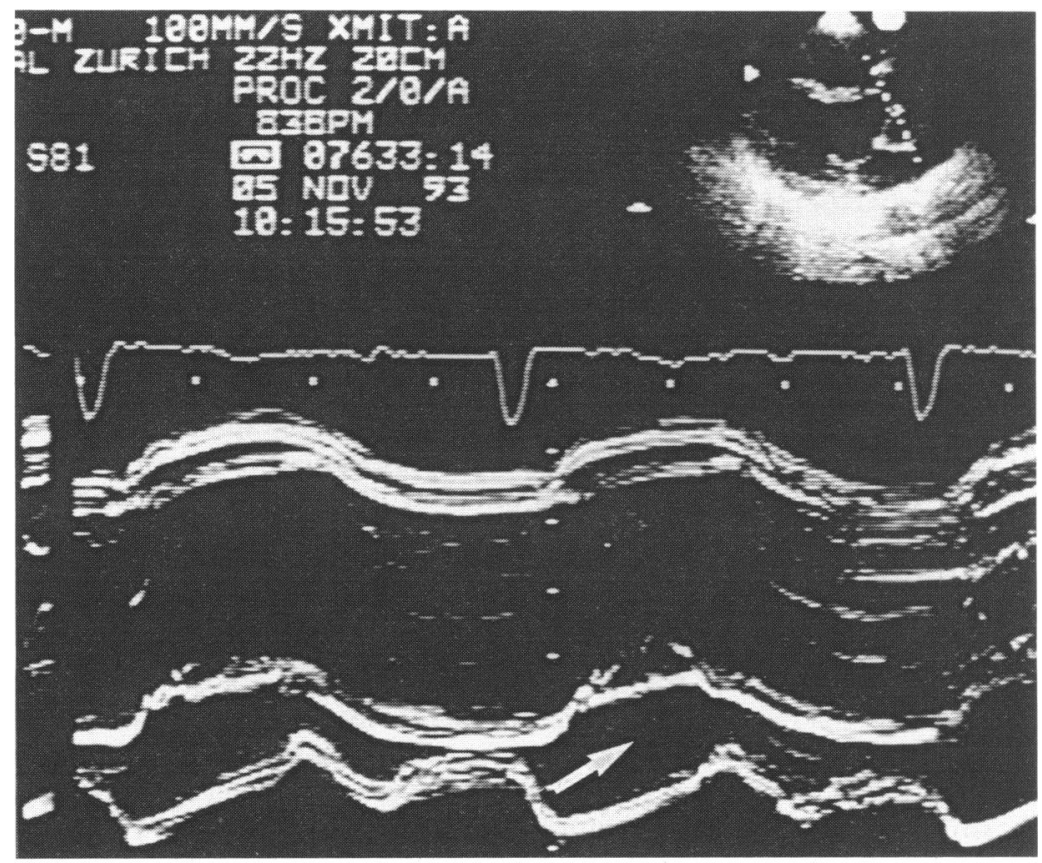

Figure 3 Cross sectionally guided $M$ mode scan (parasternal long axis view) of the same patient as in fig 2 showing the pseudoaneurysm (bold arrow) which changes in size with cardiac cycle. Distance between horizontal dots equals $200 \mathrm{~ms}$, distance between two vertical dots equals $1 \mathrm{~cm}$. A peripheral lead of the electrocardiogram is displayed on the top of the $M$ mode scan.
All patients except one were examined by transthoracic cross sectional Doppler echocardiography; one intensive care patient was investigated by transoesophageal echocardiography.

Indications for insertion of an aortic homograft were active endocarditis $(n=15)$ at time of surgery, 12 with abscess formation, two with infected aortic valves, and one with a paravalvular leak. Seven patients had a history of previously cured endocarditis: three had a perfused abscess cavity, three a paravalvular leak, and one a perforated cusp after eradication of endocarditis. Anticoagulation was undesirable in eight patients without any history of endocarditis.

\section{DEFINITION OF PSEUDOANEURYSM}

Aortic homograft pseudoaneurysm was defined as a perfused echo-free space between the native aortic wall and the aortic homograft due to partial dehiscence at the proximal suture line (figs 1-3). Communication between this space and the left ventricular outflow tract needed a systo-diastolic colour Doppler signal for visualisation. Typically, the onset of this signal within the echo-free space occurred before the onset of the systolic colour Doppler signal within the aortic homograft (fig 4).

\section{OPERATING TECHNIQUES}

Cardiopulmonary bypass was conducted in moderate hypothermia through aorto-atrial cannulation. Usually, myocardial protection was performed by continuous retrograde cold blood cardioplegia. Exposure of the oblique aortotomy was facilitated by placement of three stay sutures. After preparation of the cryopreserved allograft and resection of the native valve, the proximal suture line was performed in a continuous or interrupted manner with a polypropylene monofilament. During construction of the proximal suture, the homograft was inverted into the left ventricle. Positional traction sutures of 4.0 monofilament were placed at the top of each commissure to maintain optimal suspension. Starting at the bottom of each coronary sinus, the suture runs to the tops of each commissure, where it is brought outside the native aorta. The sutures were tied over pledgets outside the aorta. Aortic homograft was implanted as aortic valve replacement in this classic technique (type I), as aortic root reconstruction with infracoronary anastomosis of the homograft (type II) and as composite graft with reanastomosis of the coronary arteries (type III). Recently, fibrin glue has been used in 12 patients to improve adhesion of the homograft to the native aortic wall between the two suture lines. ${ }^{19}$

\section{DOPPLER ECHOCARDIOGRAPHY}

Cross sectional echocardiographic examination, colour flow, and continuous wave Doppler measurements were performed according to standard techniques with the use of a $2.5 \mathrm{MHz}$ crystal set for imaging and for continuous wave Doppler echocardiography 


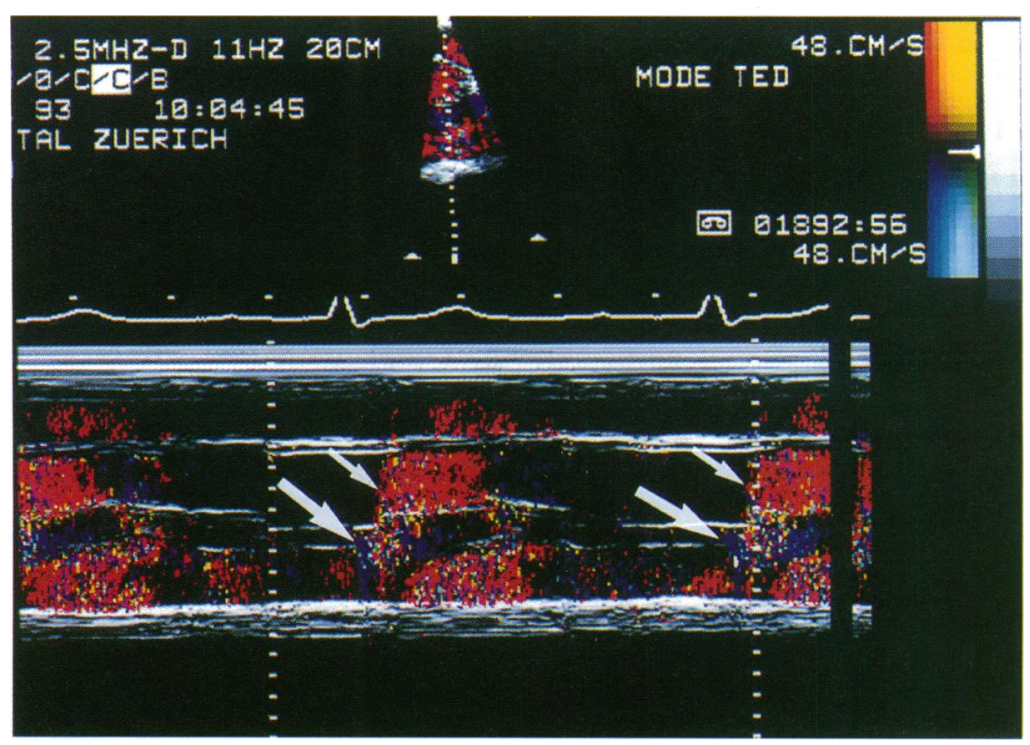

Figure 4 Colour coded Doppler flow superimposed on a cross sectionally guided $M$ mode tracing (parasternal short axis view) of the same patient as in fig 2 (four months after aortic homograft implantation): note the onset of blood flow within the pseudoaneurysm (bold arrow) begins before aortic valve opening (small arrow). Distances (horizontal and vertical dots) and electrocardiogram as in fig 3.

\section{Table 1 Clinical data}

\begin{tabular}{lrrl}
\hline & PSA & No PSA & $P$ \\
\hline Patients, n(\%) & $22(73)$ & $8(27)$ & \\
Age, years (SD) & $43(14)$ & $52(16)$ & NS \\
Follow up, months (SD) & $9(11)$ & $3(2)$ & NS \\
\hline PSA, pseudoaneurysm. & & &
\end{tabular}

(Hewlett-Packard HP Sonos 1500). All patients were studied transthoracically in standard parasternal and apical windows except one mechanically ventilated patient who underwent transoesophageal echocardiography in the intensive care unit. The leading edge technique was used for the measurement of the aortic root diameter..$^{20}$ Continuous wave Doppler interrogation of the aortic homograft and the left ventricular outflow tract was performed from the apical four chamber view; mean gradients of transvalvular blood flow were calculated using the modified Bernoulli equation. ${ }^{21}$ Homograft size was indicated as internal diameter of the aortic homograft.

\section{STATISTICAL ANALYSIS}

Results are presented as mean values and standard deviations. An unpaired $t$ test (two tailed) was used to determine the statistical difference between the two groups (pseudoaneurysm $v$ no pseudoaneurysm) regarding age, follow up (months), diameters (homograft, aortic root),

Table 2 Doppler echocardiographic data

\begin{tabular}{llll}
\hline & $P S A(n=22)$ & No PSA $(n=8)$ & $P$ \\
\hline Diameter, mm (SD) & $37(7)(\mathrm{n}=19)^{\star}$ & $33(3)(\mathrm{n}=7)^{\star}$ & NS \\
$\quad$ Aortic root & $23(2)(\mathrm{n}=20)^{\star}$ & $22(2)(\mathrm{n}=7)^{\star}$ & NS \\
$\quad \begin{array}{l}\text { Aortic homograft } \\
\text { Mean systolic pressure gradient, }\end{array} \quad$ & & \\
$\quad$ modified Bernoulli, mm Hg (SD) & $15(12)(\mathrm{n}=20)^{\star}$ & $10(4)(\mathrm{n}=7)^{\star}$ & NS \\
$\begin{array}{l}\text { Central aortic insufficiency (n) } \\
\quad \text { Mild }\end{array}$ & 19 & 8 & \\
$\quad$ Moderate & 3 & 0 & \\
\hline
\end{tabular}

PSA, pseudoaneurysm.

$\star$ Data not available in all patients. and mean transvalvular systolic gradient. Possible risk factors for development of a pseudoaneurysm including preoperative infection $v$ no infection, first operation $v$ reoperation, and operating techniques were examined by $\chi^{2}$ analysis (contingency method). $P$ values of less than 0.05 were considered to indicate a significant difference.

\section{Results}

The aortic homograft was implanted as aortic valve replacement with the classic technique (type I) in 17 patients, and in four patients as aortic root reconstruction with infracoronary anastomosis of the homograft (type II). Implantation of the aortic homograft as a composite graft was performed in nine cases (type III).

A pseudoaneurysm (up to $15 \mathrm{~mm}$ ) was observed in $73 \%$ of the patients (table 1). Their mean age was 43 (SD 14) years (range 19 to 72 ) and mean follow up was 9 (11) months (range 1 to 41 ); these values were not significantly different from those of the eight patients $(27 \%)$ without a pseudoaneurysm. In some cases, the presence of a pseudoaneurysm could already be detected a few days postoperatively. Although mean follow up was similar in both groups, follow up extended to 3.5 years after operation in patients with a pseudoaneurysm, whereas it extended only to 5 months in patients without pseudoaneurysm formation.

\section{PREOPERATIVE INFECTION}

Pseudoaneurysm occurrence was similar in patients with active or eradicated endocarditis $(73 \%)$ and in patients without a history of infectious aortic valve disease (75\%). Fourteen of 16 pseudoaneurysms in patients with an infectious history developed at the sites of preoperative abscesses or paravalvular leaks.

DOPPLER ECHOCARDIOGRAPHIC DATA (table 2) The mean size of the implanted aortic homograft was similar in both groups but patients with a pseudoaneurysm had a slightly, but not significantly, larger diameter of the aortic root. Furthermore, the mean transvalvular systolic pressure gradient tended to be higher in patients with a pseudoaneurysm. The mean systolic transvalvular pressure gradient was 14 (11) $\mathrm{mm} \mathrm{Hg}$ in 27 patients overall (measurement of mean systolic pressure gradient was not available in three patients). All patients had mild central aortic insufficiency, except three with a pseudoaneurysm who had moderate central aortic regurgitation.

OPERATING TECHNIQUES (table 3)

The technique of homograft implantation did not influence the development of a pseudoaneurysm. A pseudoaneurysm was documented in 12 patients $(71 \%)$ operated by the classic technique (type I), in three patients $(75 \%)$ with aortic root reconstruction and infracoronary anastomosis of the aortic homograft (type II operation technique), and in 
Table 3 Operating techniques

\begin{tabular}{lrrlll}
\hline & \multicolumn{2}{c}{$P S A(n=22)$} & & \multicolumn{2}{c}{ No PSA $(n=8)$} \\
\cline { 2 - 3 } \cline { 5 - 6 } & $n$ & $\%$ & & $n$ & $\%$ \\
\hline Type I $(\mathrm{n}=17)$ & 12 & 71 & & 5 & 29 \\
Type II $(\mathrm{n}=4)$ & 3 & 75 & & 1 & 25 \\
Type III $(\mathrm{n}=9)$ & 7 & 78 & & 2 & 22 \\
\hline
\end{tabular}

PSA, pseudoaneurysm; type I, classic homograft implantation technique; type II, aortic root reconstruction with infracoronary anastomosis of the aortic homograft; type III, implantation of the aortic homograft as composite graft.

There are no significant differences between the groups.

seven patients $(78 \%)$ with a homograft as composite graft (type III operation technique). The proximal suture line technique (either continuous polyprolene or interrupted suture) also could not be correlated with the incidence of pseudoaneurysm.

\section{FIRST OR REOPERATION}

Eighteen patients underwent aortic valve reoperation. They had a slightly, but not significantly, higher probability ( $83 \%$ ) of developing a pseudoaneurysm than patients operated on for the first time $(58 \%)$ ). Sixteen of the reoperated patients had undergone previous prosthetic aortic valve replacement; transaortic resection of a subvalvular membrane was performed in one patient, with plastic operation of the ascending aorta 12 years earlier; in a second patient, aortic valve commissurotomy had been performed 24 years before homograft implantation.

A 39 year old man developed recurrent endocarditis two months after implantation of an aortic homograft (because of CarpentierEdwards bioprosthetic endocarditis with $S$ aureus), with rupture of the cusp situated at the site of the right coronary sinus and perforation of the aortic annulus at the site of the non-coronary sinus causing a shunt to the left atrium. Antibiotic treatment was given for six weeks and the aortic homograft was then replaced by a new one (diameter $21 \mathrm{~mm}$ ), 3.5 months after the previous homograft implantation. Early in the postoperative period, Doppler echocardiographic examination showed a large pseudoaneurysm at the site of the right coronary sinus, with severe haemodynamic impairment (mean systolic transvalvular aortic gradient $=50 \mathrm{~mm} \mathrm{Hg}$ ). A further operation was immediately performed, with refixation of the homograft at the proximal anastomosis. Fibrin glue was used to close the prior abscess cavity. A small pseudoaneurysm was present at the site of the same coronary sinus after refixation of the aortic homograft.

\section{Discussion}

Thirty years after the first description of the use of an aortic homograft by Ross and Barratt-Boyes, ${ }^{12}$ the method has become increasingly popular because of its increased availability, improved preparation, storage and surgical techniques, and good long term results. ${ }^{346}$ Degenerative lesions or infectious complications rarely seem to be a problem after homograft aortic valve replacement or aortic root reconstruction. ${ }^{56}$ Although homo- grafts are used more often, the majority of our patients underwent prosthetic valve replacement. Thus overall 732 aortic valve replacements were performed during the study period at our institution, including patients with additional cardiovascular surgery (mitral valve reconstruction or replacement, composite graft implantation, coronary bypass grafting), and only 30 patients (age $\geqslant 16$ years) received aortic homograft implantation.

Interestingly, perfused echo-free spaces between the aortic homograft and the native aortic wall, that is, pseudoaneurysm formation, have not been reported so far as a common postoperative Doppler echocardiographic finding and a source of potential complications. In contrast, in 22 of our 30 patients (73\%) a pseudoaneurysm situated at the level of the aortic root was found after aortic valve replacement with a homograft. Florid infection at the time of operation or a paravalvular leak after eradicated infection did not influence the formation of pseudoaneurysms; however, the location of the pseudoaneurysm corresponded with the location of abscesses or paravalvular leaks in 14 of 16 cases. This interesting observation might be explained by severe tissue disturbance at the level of the aortic annulus and beneath, thus complicating the setting of sutures. Similar conditions can be found in patients with a previous aortic valve operation resulting in a slightly, but not significantly, higher probability of developing a pseudoaneurysm. Neither the operating technique (annular, infra-annular, or tube-valve homograft) nor the type of proximal suture line (continuous/interrupted) influenced the development of a pseudoaneurysm. Moreover, pseudoaneurysms could already be detected a few days after homograft implantation in the majority of our patients.

The mean Doppler echocardiographic systolic transvalvular pressure gradient was slightly, but not significantly, higher in patients with a pseudoaneurysm $(15 \mathrm{~mm} \mathrm{Hg} v 10 \mathrm{~mm}$ $\mathrm{Hg}$ ) despite similar homograft diameters (23 $\mathrm{mm} v 22 \mathrm{~mm}$ ) in both groups (with and without a pseudoaneurysm). This slightly higher systolic pressure gradient in patients with a pseudoaneurysm might be caused by homograft compression because of inflation of the echo-free space by blood; the higher pressure gradient may also reflect the higher blood flow through the aortic valve because of the presence of moderate aortic regurgitation in three patients with a pseudoaneurysm compared to only mild regurgitation in patients without a pseudoaneurysm. Left ventricular function may be considered as a further factor influencing the transvalvular pressure gradient.

In our series, the incidence of mild (27/30) and moderate (3/30) aortic regurgitation was higher than that reported by Kirklin et al, who found an initial (within one month) postoperative incidence of mild and moderate insufficiency of only $37 \%$ and $4 \%$, respectively; $59 \%$ of the operated patients had no aortic regurgitation on the initial Doppler echocardiogram. ${ }^{6}$

The mean pressure gradient of 14 (11) $\mathrm{mm} \mathrm{Hg}$ in 27 patients (mean pressure 
gradient was not available in three patients) was higher than the gradient reported by Jaffe and coworkers in 27 normally functioning homografts 7 (3) $\mathrm{mm} \mathrm{Hg} .{ }^{22}$ The lower mean pressure gradient in the report of Jaffe might be explained partly by the small number of patients in both series, or by the homograft size (12 patients with homograft sizes greater than $25 \mathrm{~mm} v$ one patient with a diameter of $26 \mathrm{~mm}$ in our series). Similar mean pressure gradients were published by Kirklin et al who found a mean pressure gradient of less than $10 \mathrm{~mm} \mathrm{Hg}$ in $77 \%$ and a gradient of between 10 and $20 \mathrm{~mm} \mathrm{Hg}$ in $17 \%$ of 112 patients up to 8.7 years after operation. ${ }^{6} \mathrm{~A}$ mean systolic pressure gradient of less than $20 \mathrm{~mm} \mathrm{Hg}$ in $94 \%$ of patients agrees well with our results (mean values of 10 and $15 \mathrm{~mm} \mathrm{Hg}$, respectively).

In our series of 30 cases, one patient also required urgent reoperation because of haemodynamically severe aortic obstruction from compression of the homograft by a pseudoaneurysm. Kirklin et al reported the need for reoperation because of partial dehiscence of the aortic homograft suture line away from the native aortic wall in one of 178 patients. ${ }^{6}$ In a series of 108 patients, Okita and coworkers described a postoperative periprosthetic leak forming a false aneurysm at the proximal suture line in one patient; this patient underwent emergency aortic root replacement with a homograft. ${ }^{17}$ Pochis and coworkers reported a similar case who presented a functional stenosis of the homograft valve caused by compression and distortion by blood transmitted directly from the left ventricle into a space between the homograft and an external cavity formed by a Dacron wrap. ${ }^{18}$ However, the overall significance of pseudoaneurysm and its surgical relevance are not yet clear and this finding has not been associated with a higher incidence of late reoperation or with major late complications in this series of patients.

\section{CONCLUSIONS}

When carefully looked for pseudoaneurysm formation appears to be a common postoperative finding after aortic valve replacement with a homograft, especially at the site of an abscess or a paravalvular leak after eradication of a prosthetic valve endocarditis.

Clinically the most significant complication in our study was compression of the homograft with obstruction of the aortic valve area in one patient. However, it is conceivable that pseudoaneurysm formation may cause additional stress at the suture line and the aortic wall with the potential risk of rupture, embolisation, and newly acquired or recurrent infection. A prospective study is necessary to determine the prognostic importance and the risks associated with pseudoaneurysm formation. Finally, modification of the surgical technique (for example, sealing the native aortic wall and the aortic homograft by application of fibrin glue between the two structures) ${ }^{19}$ may reduce the risk of dehiscence of the proximal suture line and pseudoaneurysm development.

1 Ross DN. Homograft replacement of the aortic valve. Lancet 1962;ii:487.

2 Barratt-Boyes BG. Homograft aortic valve replacement in aortic incompetence and stenosis. Thorax 1964;19: 131-50.

3 Barratt-Boyes BG, Roche AHG, Subramanyan R, Pemberton JR, Whitlock RML. Long-term follow-up of patients with the antibiotic sterilised aortic homograft patients with the antibiotic sterilised aortic homograft
valve inserted freehand in the aortic position. Circulation valve inserted free
1987;75:768-77.

4 Matsuki O, Robles A, Gibbs S, Bodnar E, Ross DN. Longterm performance of 555 aortic homografts in the aortic position. Ann Thorac Surg 1988;46:187-91.

5 Virdi IS, Monro JL, Ross JK. Eleven year experience of aortic valve replacement with antibiotic sterilised homograft valves in Southampton. Thorac Cardiovasc Surg 1986;34:277-82.

6 Kirklin JK, Smith D, Novick W, Naftel DC, Kirklin JW, Pacifico AD, et al. Long-term function of cryopreserved aortic homografts: a ten-year study. F Thorac Cardiovasc Surg 1993;106:154-66.

7 O'Brien MF, McGiffin DC, Stafford EG, Gardner MA, Pohler PF, McLachlan GJ, et al. Allograft aortic valve replacement: long-term comparative clinical analysis of the viable cryopreserved and antibiotic $4^{\circ} \mathrm{C}$ stored valves. the viable cryopreserved and antibiotic

8 Blackstone EH, Kirklin JW. Death and other time-related events after valve replacement. Circulation 1985;72: events after.

9 Ivert TSA, Dismukes WE, Cobbs LG, Blackstone EH, Kirklin JW, Bergdahl LAL. Prosthetic valve endocarditis. Circulation 1984;69:223-32.

10 Haydock D, Barratt-Boyes B, Macedo T, Kirklin JW, Blackstone E. Aortic valve replacement for active infectious endocarditis in 108 patients. F Thorac Cardiovasc Surg 1992;103:130-9.

11 Kirklin JK, Pacifico AD, Kirklin JW. Surgical treatment of prosthetic valve endocarditis with homograft aortic valve replacement. $\mathcal{F}$ Cardiac Surg 1989;4:340-7.

12 Ross D. Allograft root replacement for prosthetic endocarditis. $\mathcal{F}$ Cardiac Surg 1990;5:68-72.

13 Tuna IC, Orszulak TA, Schaff HV, Danielson GK. Results of homograft aortic valve replacement for active endoof homograft aortic valve replacement for
carditis. Ann Thorac Surg 1990;49:619-24.

14 Barbetseas J, Crawford ES, Safi HJ, Coselli JS, Quinones MA, Zoghbi WA. Doppler echocardiographic evaluation of pseudoaneurysms complicating composite grafts of the ascending aorta. Circulation 1992;85:212-22.

15 Donaldson RM, Ross DN. Composite graft replacement for the treatment of aneurysms of the ascending aorta associated with aortic valvular disease. Circulation 1982; 66:116-21.

16 Kouchoukos NT, Marshall WG, Wedige-Stecher TA. Eleven-year experience with composite graft replacement of the ascending aorta and aortic valve. $\mathcal{f}$ Thorac Cardiovasc Surg 1986;92:691-705.

17 Okita Y, Franciosi G, Matsuki O, Robles A, Ross DN. Early and late results of aortic root replacement with antibiotic-sterilised aortic homograft. $\mathcal{F}$ Thorac Cardiovasc Surg 1988;95:696-704.

18 Pochis WT, Cinquegrani MP, McManus RP, Almassi GH. Periaortic hematoma formation leading to aortic valve failure: a complication of homograft placement for secfailure: a complication of homograft placem

19 Von Segesser LK, Oechslin E, Jenni R, Turina MI. Use of glue to avoid formation of perfused recesses in aortic allograft implantation. Ann Thorac Surg 1994;57:494-5.

20 Sahn DJ, DeMaria A, Kisslo J, Weyman A. Recommendations regarding quantitation in $M$-mode echocardiography: results of a survey of echocardiographic measurements. Circulation 1978;58:1072-83.

21 Hatle L, Angelsen B. Doppler ultrasound in cardiology, 2nd ed. Philadelphia: Lea and Febiger, 1985:93.

22 Jaffe WM, Coverdale HA, Roche AHG, Brandt PWT, Ormiston JA, Barratt-Boyes BG. Doppler echocardiography in the assessment of the homograft aortic valve. $A m \mathcal{F}$ Cardiol 1989;63:1466-70. 